\title{
Reprovação Expressiva na Disciplina de Contabilidade de Custos: Quais os Possíveis Motivos?
}

\section{Resumo}

O presente artigo tem por objetivo identificar os possíveis motivos do alto índice de reprovação na disciplina de Contabilidade de Custos oferecida aos alunos do curso de graduação em Ciências Contábeis da Universidade Estadual de Maringá (UEM), representando uma média de reprovação de $42 \%$ em relação ao período de 2008 a 2013. Utilizou-se como técnica de coleta de dados questionários com questões abertas e fechadas e, quanto à estratégia de pesquisa, utilizou-se para a tabulação e análise dos dados obtidos nas questões abertas o Discurso do Sujeito Coletivo (DSC). O percentual referente aos alunos que reprovaram por nota e os alunos que reprovaram por falta são, respectivamente, de $16 \%$ e $27 \%$. Desta forma, para uma tentativa de análise parcial sobre os alunos reprovados por nota, utilizou-se da variável ansiedade, que apresentou um percentual de percepção por parte dos alunos de, aproximadamente, $60 \%$ da amostra, a partir da abordagem da Psicologia Cognitiva baseada na Teoria do Processamento da Informação. E, para a análise parcial sobre os alunos reprovados por falta, utilizou-se da variável falta de dedicação e desinteresse, que apresentou um percentual de percepção por parte dos alunos de $47 \%$ da amostra, utilizando para fundamentação a Teoria da Procrastinação.

Palavras-chave: Motivos da reprovação; Desempenho acadêmico; Contabilidade de Custos.

\author{
lasmini Turci Borges \\ Mestranda em Ciências Contábeis pela \\ Universidade Estadual de Maringá. \\ Contato: Av. Colombo, 5790, bloco C-23, \\ Zona 07. CEP.: 87020-900. Maringá-PR. \\ E-mail: iasminiborges@gmail.com
}

\begin{abstract}
Aline dos Santos
Mestranda em Ciências Contábeis pela Universidade Estadual de Maringá. Contato: Av. Colombo, 5790, bloco C-23, Zona 07. CEP.: 87020-900. Maringá-PR. E-mail: Aline.santos91@hotmail.com
\end{abstract}

\section{Kata Abbas}

Doutora em Engenharia de Produção pela Universidade Federal de Santa Catarina e Professora da Universidade Estadual de Maringá. Contato: Av. Colombo, 5790, bloco C-23, Zona 07. CEP.: 87020-900. Maringá-PR. E-mail: kabbas@uem.br

Kelly Cristina Mucio Marques Doutora em Controladoria e Contabilidade pela FEA-USP e Professora na Universidade Estadual de Maringá. Contato: Av. Colombo, 5790, bloco C-23, Zona 07. CEP.: 87020-900. Maringá-PR. E-mail: kcmmarques@uem.br

Joyce Menezes da Fonseca Tonin Mestra Contabilidade pela Universidade Federal do Paraná e Professora na Universidade Estadual de Maringá. Contato: Av. Colombo, 5790, bloco C-23, Zona 07. CEP.: 87020-900. Maringá-PR. E-mail: joycemftonin@gmail.com 


\section{Introdução}

A educação é um direito fundamental assegurado pela Constituição Federal em seu artigo n. ${ }^{\circ}$ 205, a qual determina como sendo responsabilidade do Estado e da família, envolvendo o preparo para exercício da cidadania, desenvolvimento pessoal e qualificação para o trabalho (Brasil, 1988). Nesta última abordagem, a educação em nível superior resguarda significativa importância ao promover a disseminação de conhecimentos essenciais para o exercício profissional.

Os investimentos em educação não se limitam aos valores monetários repassados pelo governo ou pagos em mensalidades, representam a propagação do saber, transcendendo fronteiras, tempo e gerações. Dada a sua vitalidade para sociedades desenvolvidas e seu poder intrínseco de transformação econômicosocial, estudos desenvolvidos para melhor acompanhar esta área têm se tornado direcionadores para políticas públicas (Costa \& Boruchovitch, 2004; Garzella, 2013; Silva, Mainier \& Passos, 2006).

Segundo Hipólito (2011), em 2009 as perdas financeiras com a evasão no ensino superior chegaram a nove bilhões de reais e cada aluno custa por volta de quinze mil reais ao ano nas universidades públicas. Para Silva Filho, Motejunas, Hipólito e Lobo (2007), a evasão estudantil no ensino superior é um problema internacional que afeta o resultado dos sistemas educacionais, sendo desperdícios sociais, acadêmicos e econômicos. A evasão anual e total depende dos níveis de reprovação e das taxas de evasão por ano ao longo do curso (Silva Filho et al., 2007). Por isso, é importante a análise dos motivos que podem levar a altos índices de reprovação, uma vez que esse fator pode gerar a evasão.

Por meio de um recente levantamento feito por estudantes do Programa de Pós-Graduação em Ciências Contábeis do Departamento de Ciências Contábeis da Universidade Estadual de Maringá (UEM), foi constatado que o índice médio de reprovação na disciplina Contabilidade de Custos, entre 2008 e 2013 , varia de $43,41 \%$ a $41,83 \%$ dos alunos matriculados, os quais reprovam por pelo menos uma vez. Para efeito de comparação, Rissi e Marcondes (2011) identificaram que o índice de reprovação na mesma disciplina na Universidade Estadual de Londrina foi de 27,78\% para o curso noturno e 28,89\% para o diurno, no ano de 2009. Vieira e Cristóvão (2009) comentam que a Universidade de Évora, em Portugal, possui um documento com orientações de combate ao insucesso escolar, especialmente direcionado às unidades curriculares, com taxas de reprovação iguais ou superiores a $25 \%$. Se comparado com esse percentual de insucesso, as taxas de reprovação encontradas na disciplina de Contabilidade de Custos são consideradas altas. No entanto, não foram encontrados estudos que relatassem os motivos da reprovação nessa disciplina, a qual faz parte da matriz curricular do curso de Ciências Contábeis.

Nesse contexto, devido aos índices de reprovação da disciplina de Contabilidade de Custos, pretende-se verificar, de forma detalhada, motivos que podem contribuir para essa situação, levantando a seguinte questão a ser respondida pela presente pesquisa: Quais motivos podem explicar o alto índice de reprovação na disciplina de Contabilidade de Custos na percepção dos alunos?

Para tanto se buscou relatar a posição dos alunos do segundo ano do curso de graduação em Ciências Contábeis frente à didática, conteúdo, carga horária e outros atributos da disciplina de Contabilidade de Custos ministrada no primeiro semestre de 2013. Paralelamente, buscou-se verificar a existência de um perfil dos alunos reprovados nesta disciplina, destacando suas personalidades, habilidades, afinidades e dificuldades. Os achados foram analisados com base na Teoria da Procrastinação e na Teoria do Processamento da Informação.

Esta pesquisa teve por objetivo identificar possíveis motivos para o alto índice de reprovação na disciplina de Contabilidade de Custos oferecida aos alunos do curso de graduação em Ciências Contábeis da Universidade Estadual de Maringá. Como contribuição teórica, a pesquisa apresenta uma discussão dos motivos que podem estar ligados à reprovação na percepção dos alunos, respaldados e explicados por teorias. Como contribuição prática, os achados da pesquisa trazem à tona a necessidade de reflexão sobre o processo de ensino/aprendizagem, focando o papel do aluno para entender os problemas e verificar de que forma os professores e as instituições podem auxiliar na sua resolução. Destaca-se que, embora o estudo tenha sido realizado em apenas uma instituição de ensino, ele pode oferecer parâmetros para outras instituições avaliarem sua situação, além de provocar a reflexão com o corpo docente sobre possíveis causas de reprovação. 


\section{Teoria da Procrastinação}

A palavra procrastinação significa "Deixar para outro dia, ou para um tempo futuro, por motivos repreensíveis; adiar." (Michaelis, 2014). O ato de procrastinar pode ser considerado tão antigo quanto a própria academia. Até mesmo pode-se dizer que a procrastinação é paralela à evolução da civilização humana, quando os primeiros habitantes se agrupavam em pequenos clãs e dentro destes, algum indivíduo tomava a decisão de adiar desnecessariamente alguma tarefa.

Diante da evolução das civilizações, as demandas dos agentes culturais aumentaram, compromissos surgiram, tarefas, horários a serem cumpridos e, juntamente, as oportunidades de procrastinação também cresceram. Adiar tarefas que deveriam ser tratadas como prioritárias em função da realização de outras tarefas com menos importância no momento, postergando a tomada de decisão e as tarefas necessárias para o alcance de um determinado objetivo, pode ser visto como uma tendência comportamental chamada de procrastinação. Com a revolução industrial, o ato de procrastinação ganhou uma maior visibilidade devido à crescente relação entre o uso eficaz do tempo e o valor social do indivíduo (Knaus, 2000).

Conforme Fontes (2012), a procrastinação é dividida em dois fatores: quanto ao uso eficaz do tempo, é notória esta necessidade em ambientes acadêmicos. O convívio diário dos alunos com a realização de inúmeras tarefas curriculares, testes, exames e provas de diferentes disciplinas, além do ritmo de trabalho cadenciado pelos seus inevitáveis prazos de cumprimento, corroboram para que o tempo seja devidamente planejado e organizado. Outro fator é a presença da grande influência social a que estes alunos estão sujeitos nos ambientes acadêmicos, que é por si só um aspecto contínuo de sentimentos e acontecimentos que poderão corroborar e ser determinantes para estimular comportamentos procrastinatórios por parte deles.

Para Enumo e Kerbauy (1999), a procrastinação acadêmica pode ser apresentada de diversas formas, como: o comportamento de postergar a realização de tarefas, a divergência entre o relato sobre a intenção de realizar a tarefa e a sua real realização, substituindo-a por outras atividades, e a não realização, pelo medo de falhar. Uma característica dos alunos que procrastinam é o corriqueiro ato de se dedicarem à realização de suas tarefas somente próximo do prazo limite para o cumprimento delas (Fontes, 2012), aumentando assim as chances de falha ou obtendo um desempenho não satisfatório.

Alguns estudos anteriores foram desenvolvidos com o intuito de relacionar a procrastinação acadêmica com o desempenho acadêmico. A Tabela 1 apresenta um resumo de alguns dos estudos anteriores que encontraram associação sobre o efeito da procrastinação no desempenho acadêmico. Muitos estudos constataram que a procrastinação acadêmica está negativamente relacionada com o desempenho acadêmico; já outros não encontraram nenhuma associação entre eles. Para cada estudo apresentado, estão identificados, de forma sintética, o tamanho da amostra, a medida de procrastinação, a medida do desempenho e o resumo dos resultados (Rotenstein, Davis \& Tatum, 2009). 
Tabela 1

Estudos sobre os efeitos da procrastinação acadêmica no desempenho acadêmico

\begin{tabular}{|c|c|c|c|c|}
\hline Estudo & Amostra & Medida de Procrastinação & $\begin{array}{l}\text { Medida de } \\
\text { Desempenho }\end{array}$ & Resultados \\
\hline $\begin{array}{l}\text { Lloyd e } \\
\text { Knutzen (1969) }\end{array}$ & 35 & $\begin{array}{l}\text { Quantidade antecipada de } \\
\text { tempo que os alunos entregam } \\
\text { uma quantidade apreciável de } \\
\text { trabalho em sala de aula. }\end{array}$ & "Course grade" & Correlação negativa forte. \\
\hline $\begin{array}{l}\text { Schwartz } \\
\text { (1976) }\end{array}$ & 24 & $\begin{array}{l}\text { Quantidade de tempo que os } \\
\text { alunos levaram para concluir um } \\
\text { curso de autoestudo. }\end{array}$ & Nota do teste inicial & $\begin{array}{l}\text { Os melhores alunos não } \\
\text { apresentavam procrastinação. }\end{array}$ \\
\hline $\begin{array}{l}\text { Henneberry } \\
\text { (1976) }\end{array}$ & 304 & $\begin{array}{l}\text { Velocidade em que os alunos } \\
\text { começaram um sistema de } \\
\text { instrução personalizada. }\end{array}$ & $\begin{array}{l}\text { Nota final; diferença } \\
\text { entre o grau de } \\
\text { expectativa atual e o } \\
\text { esperado }\end{array}$ & $\begin{array}{l}\text { Correlação positiva e significativa; } \\
\text { estudantes abaixo da média } \\
\text { foram mais prejudicados pela } \\
\text { procrastinação do que os } \\
\text { estudantes acima da média. }\end{array}$ \\
\hline $\begin{array}{l}\text { Semb, Glick, e } \\
\text { Spencer (1977) }\end{array}$ & 159 e 80 & $\begin{array}{l}\text { Conclusão das unidades iniciais } \\
\text { de trabalho no curso. }\end{array}$ & $\begin{array}{l}\text { Desempenho no } \\
\text { curso }\end{array}$ & $\begin{array}{l}\text { Os alunos procrastinadores são } \\
\text { mais propensos a ter um mau } \\
\text { desempenho no curso e mais } \\
\text { propensos a abandonar o curso } \\
\text { (medida descritiva apenas). }\end{array}$ \\
\hline
\end{tabular}

Fonte: tradução livre, adaptado de Rotenstein et al. (2009)

No Brasil, o estudo de Ribeiro, Avelino, Colauto e Casa Nova (2014) teve como objetivo investigar a relação entre o comportamento procrastinador e o desempenho acadêmico de alunos do curso de graduação em Ciências Contábeis da Universidade Federal do Paraná. Como resultado, verificou-se que os escores normalizados sugerem que estudantes com altos níveis de procrastinação tendem a ter seu desempenho escolar reduzido.

Existem atualmente inúmeras pesquisas que estão sendo desenvolvidas com o objetivo de desvendar a procrastinação acadêmica, envolvendo diversas variáveis de investigação, como: a baixa autoeficácia; o papel da esperança como uma estratégia de enfrentamento; o uso da internet como problema em estudantes universitários; a procrastinação acadêmica em estudantes universitários relacionada ao perfeccionismo e transtorno obsessivo; personalidade; procrastinação digital; diferença de gêneros; autoestima; e autodesvantagens, entre outros (Specter \& Ferrari, 2000; Beck, Koons \& Milgrim, 2000; Burns, Dittmann, Nguyen \& Mitchelson, 2000; Brownlow \& Reasinger, 2000; Fee \& Tangney, 2000; Specter \& Ferrari, 2000; Jackson, Weiss \& Lundquist, 2000; Knaus, 2000; Meyer, 2000; Onwuegbuzie, 2000; Owens \& Newbegin, 2000; Pychyl, Lee \& Blunt, 2000; Howell, Watson, Powell \& Buro 2006; Alexander \& Onwuegbuzie, 2007; Klassen, Krawchuk \& Rajani, 2008; Rotenstein et al., 2009; Kağan, Çakir, İlhan \& Kandemir, 2010; Conceição, 2011; Odaci, 2011; Fontes, 2012).

Recentemente um estudo sobre procrastinação acadêmica em alunos de pós-graduação em Contabilidade, desenvolvido por Rotenstein et al. (2009, p. 231), teve como objeto de estudo tarefas para a realização em casa de forma on-line, os resultados indicaram "[...] uma correlação negativa significativa entre a procrastinação acadêmica e o desempenho acadêmico." 


\section{Ansiedade em Situações de Avaliação, Ansiedade Escolar e a Abordagem da Psicologia Cognitiva Baseada na Teoria do Processamento da Informação}

A percepção de que o estado emocional ou psicológico do ser humano tem relação direta com o seu desempenho quando submetido a situações diversas de avaliações, soa muito natural nos tempos atuais. Tal fenômeno vem sendo estudado por vários pesquisadores, principalmente da área da Psicologia (José \& Silva, 1989; Wigfield \& Eccles, 1989; Costa \& Boruchovitch, 2004; Borralha, 2012).

Estudantes ansiosos também podem apresentar baixa habilidade estudantil e dificuldades em organizar materiais, por consequência, não processam adequadamente as informações apresentadas a eles durante as aulas. Tal situação corrobora para que o desempenho nas avaliações não seja tão favorável a estes alunos, visto que quanto menos adequadamente as informações são processadas, menor será o entendimento sobre estas (Culler \& Holahan, 1980; Benjamin, Mckeachie, Lin \& Holinger, 1981).

A ansiedade escolar foi alvo intenso de pesquisas entre as décadas de 1960 a 1970 e, após esse período, a grande maioria das pesquisas desenvolvidas no contexto acadêmico parte das investigações realizadas pelos teóricos da Psicologia Cognitiva baseada no Processamento da Informação. Tais pesquisadores defendem que a utilização de forma adequada de estratégias de aprendizagem e a manutenção do estado de satisfação interna favorecem o desempenho escolar. No que se refere ao estado de satisfação interna, englobam-se o controle de diversas variáveis, como a motivação que o indivíduo tem de aprender, as atribuições de causalidade dadas para os eventos de sucesso e fracasso escolar, o controle da ansiedade, entre outros (Costa \& Boruchovitch, 2004).

Aos adeptos da abordagem do processamento da informação, a ansiedade assume o papel como sendo um constructo multidimensional, formado por dois aspectos distintos, mas que têm relação entre si: a preocupação e a emotividade. O primeiro aspecto, a preocupação, tem referência nas expectativas negativas que o indivíduo tem sobre si mesmo, preocupação referente às consequências potenciais, ou seja, referem-se ao componente cognitivo. O segundo aspecto, a emotividade, tem referência na parte fisiológica do indivíduo, como sintomas físicos, sentimentos ligados a sensação de desprazer, nervosismo e tensão (Wigfield \& Eccles, 1989; Costa \& Boruchovitch, 2004).

Para tentar explicar o baixo desempenho em provas de alunos ansiosos, surgiram duas interpretações não excludentes e que se complementam: o primeiro modelo denominado Interferência (Wine, 1971; Wigfield \& Eccles, 1989) e o segundo modelo denominado déficit (Benjamin et al., 1981). A primeira interpretação, pelo modelo denominado Interferência, apresenta e defende a ideia de que em situações de tensão, a capacidade de relembrar ou recuperar um conteúdo aprendido em momentos anteriores pode ser interferido pela ansiedade (Costa \& Boruchovitch, 2004). Em seu estudo, os autores Wigfield e Eccles (1989) ressaltam que indivíduos com alta ansiedade tendem a dividir sua atenção entre as tarefas que estão realizando e suas inquietações de como as estão realizando. Assim, concentram-se menos nas suas tarefas, e suas performances acabam por serem inferiores às dos demais indivíduos. Conclui-se que o processo de aprendizagem ocorreu, mas o aluno, devido à ansiedade em função da situação de avaliação, perde a capacidade de demonstrar o que foi aprendido.

Para a segunda interpretação, o modelo denominado déficit, a relação da ansiedade passa a ser com o início e progresso do processo de aprendizagem, contemplando os hábitos de estudo e as estratégias de aprendizagem (Costa \& Boruchovitch, 2004). Os pesquisadores que defendem tal modelo teórico alegam que existem duas explicações possíveis para que alunos altamente ansiosos apresentem baixo desempenho: a ausência de métodos eficientes nos hábitos de estudo e a ausência de métodos eficientes nas estratégias de aprendizagem que são utilizadas para a preparação de situações de avaliação (Costa \& Boruchovitch, 2004). Desta forma, as ineficiências ocorrem no momento da aquisição do conhecimento, e também, no momento de armazenamento do mesmo. Ainda segundo Costa e Boruchovitch (2004), pesquisas estão demonstrando que os alunos pouco ansiosos possuem hábitos de estudo e estratégias para a preparação de situações de avaliação mais adequados dos que comparado aos alunos muito ansiosos, que não possuem qualidade na sua dedicação aos estudos e sofrem com o baixo desempenho, resultado deste processo deficiente. 
Retomando a relação de complementaridade destas duas interpretações, a da Interferência e do déficit, uma terceira hipótese proposta foi a da capacidade de processamento cognitivo limitada. Ao adotar a ideia de que os indivíduos ansiosos possuem uma capacidade de processamento de informação limitada, houve a consideração de que o componente cognitivo da ansiedade consumiria parte desta capacidade e as necessidades de realização das tarefas consumiriam a outra parte. Tal situação interferiria no processo de aprendizagem, pois excederia a capacidade de processamento de informação disponível naquele momento, tendo assim como consequência o mau desempenho do aluno nas avaliações (Costa \& Boruchovitch, 2004).

\section{Metodologia}

O curso de graduação em Ciências Contábeis da UEM foi criado pela Resolução nº 07/72, do Conselho Universitário, em 30 de outubro de 1972. A partir do primeiro semestre de 1986, passou a ser oferecido também no campus regional de Cianorte. Atualmente, o curso totaliza uma oferta de 160 vagas, sendo 120 para a sede em Maringá ( 80 noturno e 40 diurno) e 40 para o campus regional de Cianorte (noturno). A pesquisa foi elaborada com dados dos alunos do curso de Maringá.

A matriz curricular do curso conta com disciplinas ofertadas pelo Departamento de Ciências Contábeis juntamente com outros departamentos, entre eles, o de Administração, de Economia, de Matemática, entre outros. As disciplinas ofertadas podem ser anuais ou semestrais, sendo a duração do curso com um prazo mínimo de conclusão de 4 anos e máximo de 7 anos.

Especificamente no segundo semestre do curso de graduação ou primeiro ano da graduação, os alunos contam com 4 (quatro) disciplinas que são ministradas pelos professores do Departamento de Ciências Contábeis, sendo elas: Contabilidade Geral I, Contabilidade Geral II, Iniciação à Pesquisa em Contabilidade e Contabilidade de Custos. Dentre estas, por meio de uma escolha aleatória, a presente pesquisa teve como objeto de estudo a disciplina de Contabilidade de Custos. Esta conta com sua matriz curricular voltada ao ensino referente às terminologias, conceitos e classificações que são rotineiramente utilizadas em Custos, elementos que compõem os custos, o método de custeio por absorção, que é o único aceito pela Legislação do Imposto de Renda, e os sistemas de produção (Ordem de Produção, Processo ou Contínuo e Produção Conjunta).

O alto índice de reprovação na disciplina de Contabilidade de Custos constitui, evolutivamente, uma inquietação por parte dos docentes e de todo o departamento do curso de graduação em Ciências Contábeis da UEM. Tal problema tem sido alvo de discussão e tem instigado cada vez mais uma investigação, a fim de tentar identificar causas e perfis dos discentes que compõem o corpo de reprovados.

Especificamente em relação ao período de 2008 a 2013, é possível observar o alto índice de reprovação nesta disciplina, aproximadamente uma média de $42 \%$, enquanto que os aprovados representam em média $53 \%$, e os outros $5 \%$ de dividem entre evasões e trancamento de matrícula. Na Figura $1 \mathrm{~m}$ apresenta-se a distribuição e a evolução dos alunos alocados em aprovados, reprovados, evasão e trancamento. 


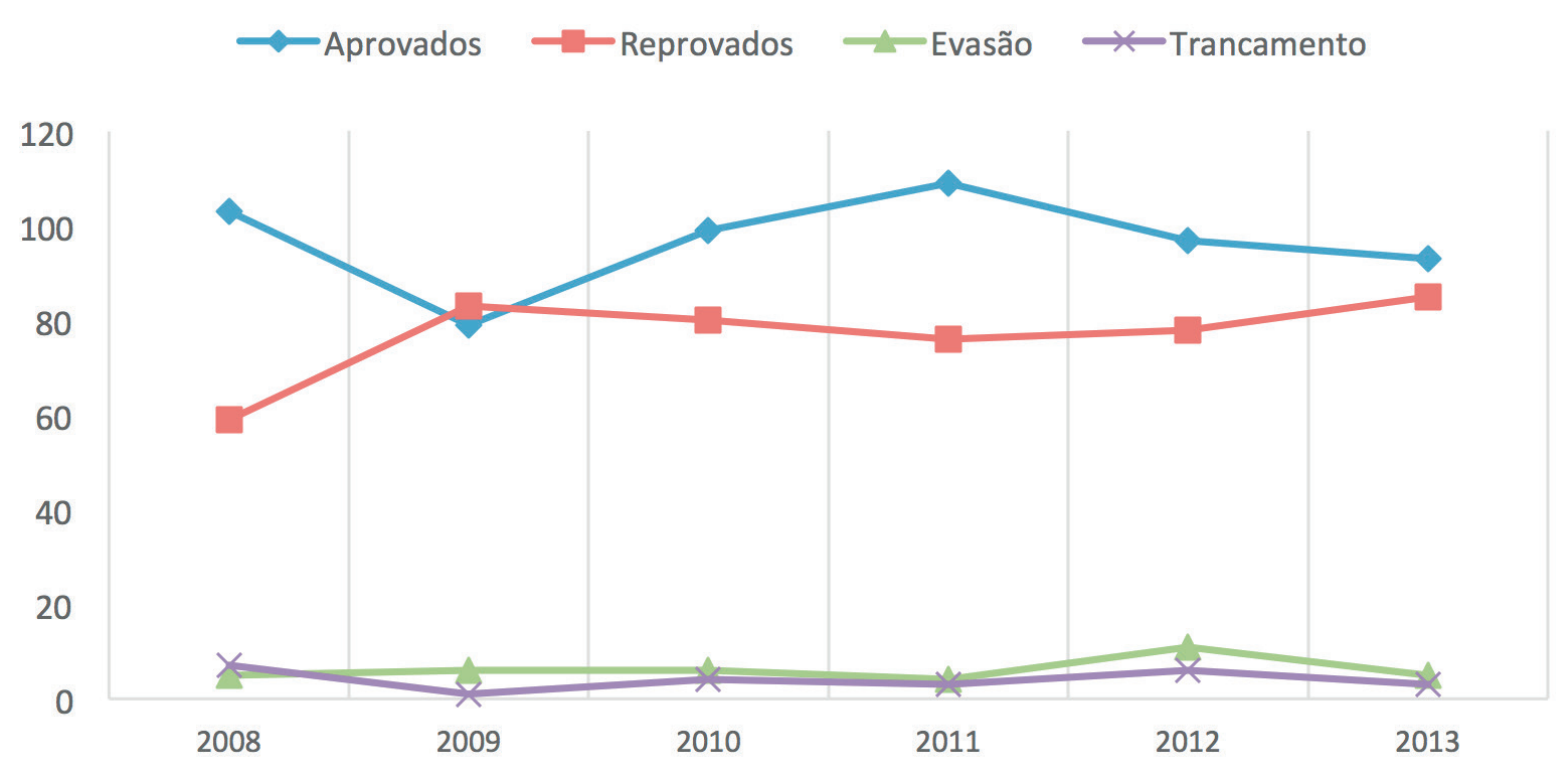

Figura 1. Evolução dos alunos na disciplina de Contabilidade de Custos

Os dados são relativos ao período de 2008 a 2013 e mostra como a curva referente aos alunos reprovados na disciplina teve uma alta relativa do ano de 2008 para o ano de 2009 e, após esta mudança, tem se mantido estável em um nível consideravelmente alto.

Para a realização da pesquisa, a técnica de coleta de dados utilizada foi a aplicação de questionário, sendo composto por dois blocos. O primeiro contém cinco questões abertas, que, segundo Mattar (2001) ,possui como vantagens o estímulo à cooperação do respondente e proporcionam ao pesquisador dados significativos. O segundo bloco, usado para a construção de perfis de personalidade, foi composto por quinze questões fechadas, que possui como vantagem o fato de ser altamente objetivo e proporcionar um menor risco de parcialidade por conta do pesquisador (Mattar, 2001).

Foi realizado o pré-teste do questionário, sendo este aplicado com 3 alunos que não faziam parte da amostra. Alguns dos objetivos, ao se aplicar o pré-teste, estão relacionados a cronometrar o tempo, confirmar o entendimento das perguntas por parte dos respondentes e verificar se a forma e sequência das perguntas estão coerentes, entre outros (Mattar, 2001). O tempo médio de resposta do questionário é de seis minutos e, por meio do pré-teste, algumas questões foram reestruturadas para melhor entendimento dos pesquisados.

A aplicação dos questionários ocorreu de forma presencial em junho de 2014 na instituição de ensino alvo desta pesquisa. A amostra não probabilística foi composta por 102 acadêmicos do segundo ano da graduação em Ciências Contábeis.

Quanto à estratégia de pesquisa, utilizou-se para a tabulação e análise dos dados obtidos nas questões abertas o Discurso do Sujeito Coletivo (DSC). Segundo Lefèvre, Lefèvre e Marques (2009), o DSC pode ser definido como uma técnica utilizada para reunir em um discurso único, redigido na primeira pessoa do singular, por meio do processamento de depoimentos, conteúdos com sentidos semelhantes.

O objetivo do DSC, de acordo com Martins e Theóphilo (2007), é sintetizar os pensamentos dos entrevistados de maneira encadeada, partindo de um conjunto de resposta sobre um determinado tema que se busca compreender, obtido em entrevistas de maneira discursiva, constituindo assim um discurso coletivo.

Para se alcançar a correta constituição do DSC, Lefèvre e Lefèvre (2005) apresentam como figuras metodológicas alguns instrumentos ou passos a serem seguidos, que são: expressões-chaves, ideias centrais, ancoragem e o próprio DSC. 
As expressões-chaves são pedaços, trechos ou transcrições literais do discurso e devem ser diferenciadas ou destacadas pelo autor. As ideias centrais são apresentadas como um nome ou expressão linguística que revela e descreve o sentido de cada um dos discursos analisados. Em relação às ancoragens, são as manifestações linguísticas de forma explícita de uma dada teoria, ou ideologia, ou crença que o autor do discurso professa e é usada pelo enunciador para "enquadrar" uma situação específica. E, por fim, a junção de pensamentos em comum sobre um dado tema resulta em um DSC, ou seja, um discursosíntese redigido na primeira pessoa do singular e composto pelas expressões-chaves que têm a mesma ideia central ou ancoragem (Lefèvre \& Lefèvre; 2005). Na Tabela 2, apresentam-se, de forma compacta, os instrumentos de análise de discurso.

Tabela 2

Instrumentos de Análise de Discurso

\begin{tabular}{lll}
\multicolumn{1}{c}{ Expressões-chaves } & Ideias Centrais & Ancoragem \\
\hline $\begin{array}{l}\text { Copiar integralmente o conteúdo de } \\
\text { todas as respostas (por questão). }\end{array}$ & $\begin{array}{l}\text { Identificar as ideias centrais; pode-se } \\
\text { ter mais de uma em cada resposta. }\end{array}$ & $\begin{array}{l}\text { Só devem ser consideradas as } \\
\text { ancoragens que estiverem presentes } \\
\text { concreta e explicitamente. }\end{array}$ \\
\hline
\end{tabular}

Fonte: adaptado de Lefèvre e Lefèvre (2005, p. 47)

Por meio desta estratégia de pesquisa, este estudo buscou também expressar a opinião, o posicionamento ou pensamento sobre quais as possíveis causas ou motivos dos alunos reprovarem na disciplina de Contabilidade de Custos.

\section{Apresentação e Discussão dos Resultados}

A partir das respostas obtidas nos 102 questionários, a primeira etapa da análise foi contemplada pela leitura, transcrição literal das respostas e tabulação dos dados obtidos. A partir desta etapa, houve a aglomeração dos perfis dos respondentes e a análise mais aprofundada, permitindo, assim, a criação de um possível perfil para os alunos aprovados e para os alunos reprovados na disciplina de Contabilidade de Custos.

Juntamente com a análise dos dados, foi possível o desenvolvimento de um desenho da pesquisa (Figura 2), partindo do objetivo principal deste estudo, que é o índice de reprovação na disciplina de Contabilidade de Custos. Posteriormente, surgiram dois desdobramentos referentes ao objetivo principal, sendo estes o percentual referente aos alunos que reprovaram por nota e os alunos que reprovaram por falta, respectivamente, $16 \%$ e $27 \%$.

Para cada desdobramento referente ao percentual de reprovação, após as análises das respostas, foi possível observar que existem duas vertentes de possíveis causas para a reprovação desses alunos, classificadas neste estudo como dificuldade e desinteresse. Partindo então dessas duas vertentes encontradas, a primeira está relacionada com algumas das possíveis variáveis: adaptação à universidade, dificuldade com cálculos, interpretação de texto e ansiedade, entre outras. Já a segunda vertente, o desinteresse, está relacionada com algumas das possíveis variáveis, como outras prioridades por parte do aluno: frequência do aluno nas aulas, outros interesses que não estão de acordo com a disciplina, falta de dedicação e desinteresse, entre outras.

Ainda vale ressaltar a grande relação apresentada nas análises entre as vertentes "dificuldade" e "desinteresse". A presença da vertente "dificuldade" pode corroborar o aparecimento do desinteresse por parte do aluno, levando, dessa forma, a sua reprovação. 


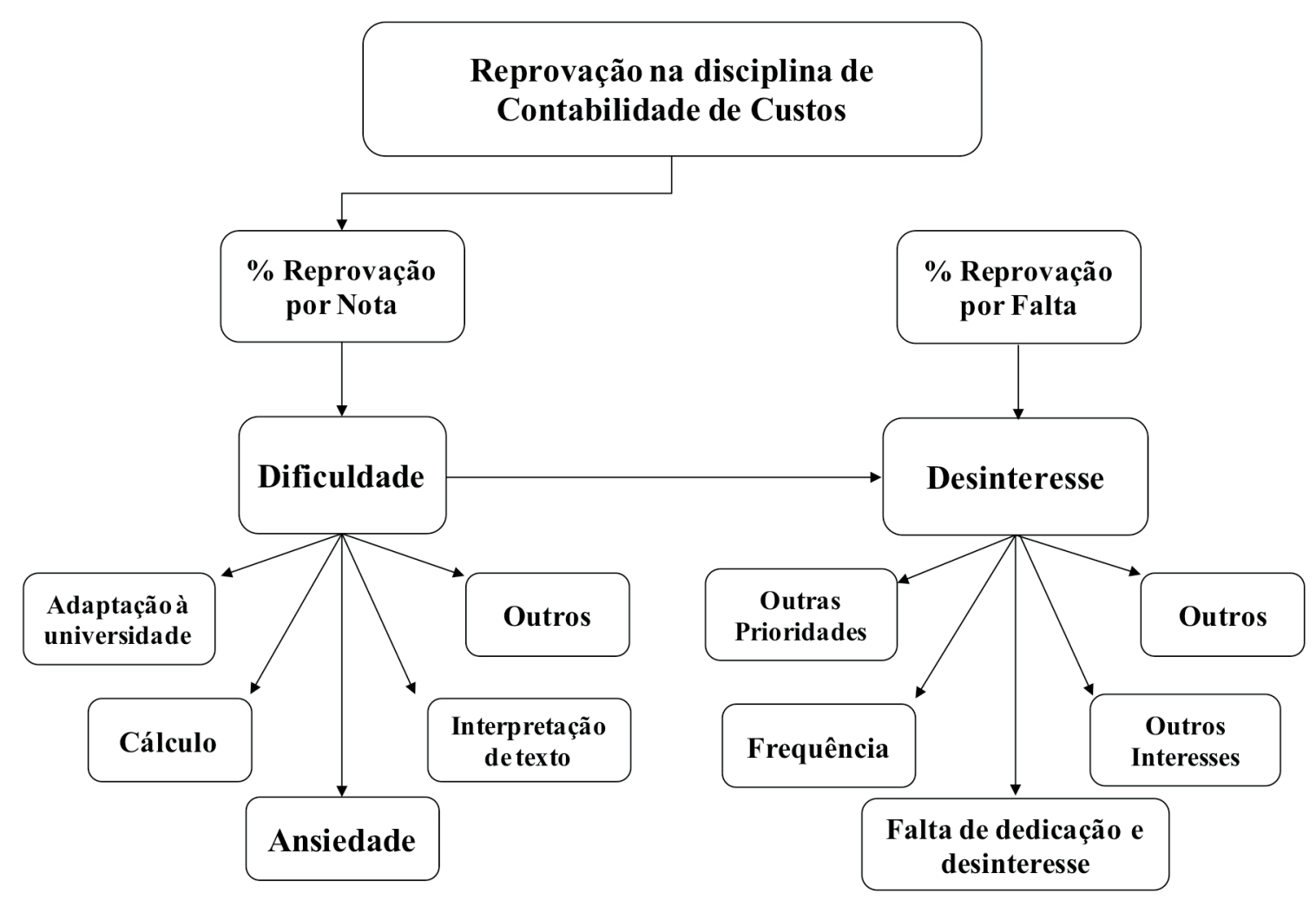

Figura 2. Desenho da pesquisa

Como uma tentativa de análise parcial sobre os alunos reprovados por nota, utilizou-se a variável "ansiedade" como possível colaboradora, a partir da abordagem da Psicologia Cognitiva baseada na Teoria do Processamento da Informação. E, para a análise parcial sobre os alunos reprovados por falta, utilizouse a variável "falta de dedicação" e "desinteresse", com sua fundamentação na Teoria da Procrastinação.

\subsection{Falta de Dedicação, Desinteresse e sua Relação com a Teoria da Procrastinação}

Dentro das opções elencadas pelos respondentes como possíveis causas ou motivos que levam os alunos à reprovação na disciplina de Contabilidade de Custos, como demonstrado na Tabela 3, cabe dar destaque à falta de dedicação, ao desinteresse e também à complexidade da disciplina. No que tange a esta última, a maioria das justificativas foi pelo fato de que a disciplina demanda envolvimento com cálculos e muitos detalhes específicos de cada método de custeio, sendo considerada por alguns alunos como "muito difícil". 
Tabela 3

Possíveis causas de reprovação na disciplina de Contabilidade de Custos

\begin{tabular}{|c|c|c|}
\hline Possíveis Causas & Frequência & $\%$ \\
\hline Adaptação à Universidade & 3 & $1,8 \%$ \\
\hline Ansiedade ou nervosismo em prova & 1 & $0,6 \%$ \\
\hline Assimilação & 2 & $1,2 \%$ \\
\hline Complexidade da disciplina & 20 & $11,7 \%$ \\
\hline Compreensão & 16 & $9,4 \%$ \\
\hline Curto tempo de duração & 13 & $7,6 \%$ \\
\hline Dedicação dos professores & 4 & $2,3 \%$ \\
\hline Dificuldade & 1 & $0,6 \%$ \\
\hline Dificuldade com cálculos & 2 & $1,2 \%$ \\
\hline Dificuldades pessoais & 1 & $0,6 \%$ \\
\hline Dificuldades & 1 & $0,6 \%$ \\
\hline Falta de conhecimento na prática & 6 & $3,5 \%$ \\
\hline Falta de dedicação & 59 & $34,5 \%$ \\
\hline Falta de interesse & 21 & $12,3 \%$ \\
\hline Frequência & 3 & $1,8 \%$ \\
\hline Interpretação & 3 & $1,8 \%$ \\
\hline Mais exercícios & 1 & $0,6 \%$ \\
\hline Método de ensino do professor & 8 & $4,7 \%$ \\
\hline Outras prioridades & 1 & $0,6 \%$ \\
\hline Outros interesses & 4 & $2,3 \%$ \\
\hline Prática de exercícios & 1 & $0,6 \%$ \\
\hline Total Geral & 171 & $100,0 \%$ \\
\hline
\end{tabular}

Quanto à falta de dedicação e o desinteresse por parte de aluno, os aspectos frequentemente elencados pelos respondentes foram a falta de resolução de exercícios, a falta de interesse do aluno em participar da aula, a frequência com que o aluno assistia às aulas e a falta de tempo dedicada aos estudos fora e, até mesmo, dentro da sala de aula. É possível retomar parte do que a Teoria da Procrastinação no âmbito acadêmico apresenta, que, segundo Enumo e Kerbauy (1999), pode ser apresentada de diversas formas, como: o comportamento de postergar a realização de tarefas, a divergência entre o relato sobre a intenção de realizar a tarefa e sua real realização, substituindo-a por outras atividades, e a não realização pelo medo de falhar.

Uma característica dos alunos que procrastinam é o corriqueiro ato de se dedicarem à realização de suas tarefas somente próximo do prazo limite para o seu cumprimento (Fontes, 2012), aumentando assim as chances de falha ou obtendo um desempenho não satisfatório. Ainda esse comportamento de postergar a realização de tarefas afeta diretamente a frequência do aluno em sala de aula, visto que, ao colocar outras atividades no lugar das atividades acadêmicas, o aluno pode acumular faltas durante o período letivo e, ao final, obter uma reprovação por falta. Para Ribeiro et al. (2014), os reflexos do comportamento procrastinador podem variar de um simples transtorno até perdas financeiras significativas e, embora a procrastinação possa ser entendida como um fenômeno que se manifesta de modo voluntário, tratando-se, portanto, de uma decisão individual, tal comportamento implica consequências negativas para o estudante, uma vez que a vida deste se caracteriza pelo cumprimento de prazos.

Fontes (2012) ressalta que a procrastinação é um fenômeno que pode ter características permanentes ou temporais, podendo ser crônico ou disfuncional a partir do momento em que os seus efeitos bloqueiam recorrentemente a própria condição de executar tarefas. O resultado da pesquisa de Solomon e Rothblum (1984) 
apontou que a procrastinação não é somente um déficit nos hábitos de estudo ou na administração do tempo, mas envolve uma interação complexa de componentes comportamentais, cognitivos e afetivos. Percebe-se, deste modo, que este é um problema que pode contribuir para o baixo desempenho na realização de tarefas.

Outro motivo também ligado à procrastinação acadêmica e que pode levar o aluno a abandonar a disciplina, obtendo a reprovação por falta, é o mau desempenho logo no início do período da disciplina ao postergar a realização das tarefas ou, até mesmo, postergar o ato em si de estudar; o aluno obtém um desempenho extremamente insatisfatório e o sentimento de falha leva-o ao abandono da disciplina, corroborando assim para que este reprove por falta. O estudo de Sampaio e Bariani (2011) registrou que sentimentos, como ansiedade, preocupação e autodepreciação, estavam presentes nos alunos que procrastinavam, indicando que esse ato afeta de modo negativo a vida do indivíduo.

Estudos constataram que a procrastinação acadêmica está negativamente relacionada com o desempenho acadêmico (Lloyd \& Knutzen, 1969; Ackerman \& Gross, 2005), inclusive entre estudantes de Contabilidade (Rotenstein et al., 2009). Esta pesquisa, por não utilizar de nenhum modelo de medida de procrastinação ou medida de desempenho, não pode colaborar de forma direta para a constatação desta relação. Entretanto, colabora de uma forma indireta, pois buscou dos alunos, fonte desta amostra, qual o pensamento sobre os possíveis motivos ou causas da reprovação da disciplina Contabilidade de Custos e, juntamente com os resultados, a aparição ressaltada sobre a procrastinação acadêmica corrobora para a necessidade de pesquisas com as medidas de procrastinação.

\subsection{Ansiedade e sua Relação com o Desempenho Durante as Avaliações: Psicologia Cognitiva Baseada na Teoria do Processamento da Informação.}

Como já mencionado, a relação entre ansiedade e desempenho em situações pertinentes à avaliação, tem conquistado sua devida atenção perante os estudiosos. Analisando os dados encontrados no bloco II do questionário, percebe-se que grande parte dos respondestes realmente atesta a relação acima referida.

A Figura 3 se refere às respostas obtidas na questão de número 18: Você sente nervosismo ou ansiedade durante as provas?

\section{Você sente nervosismo ou ansiedade durante as provas?}

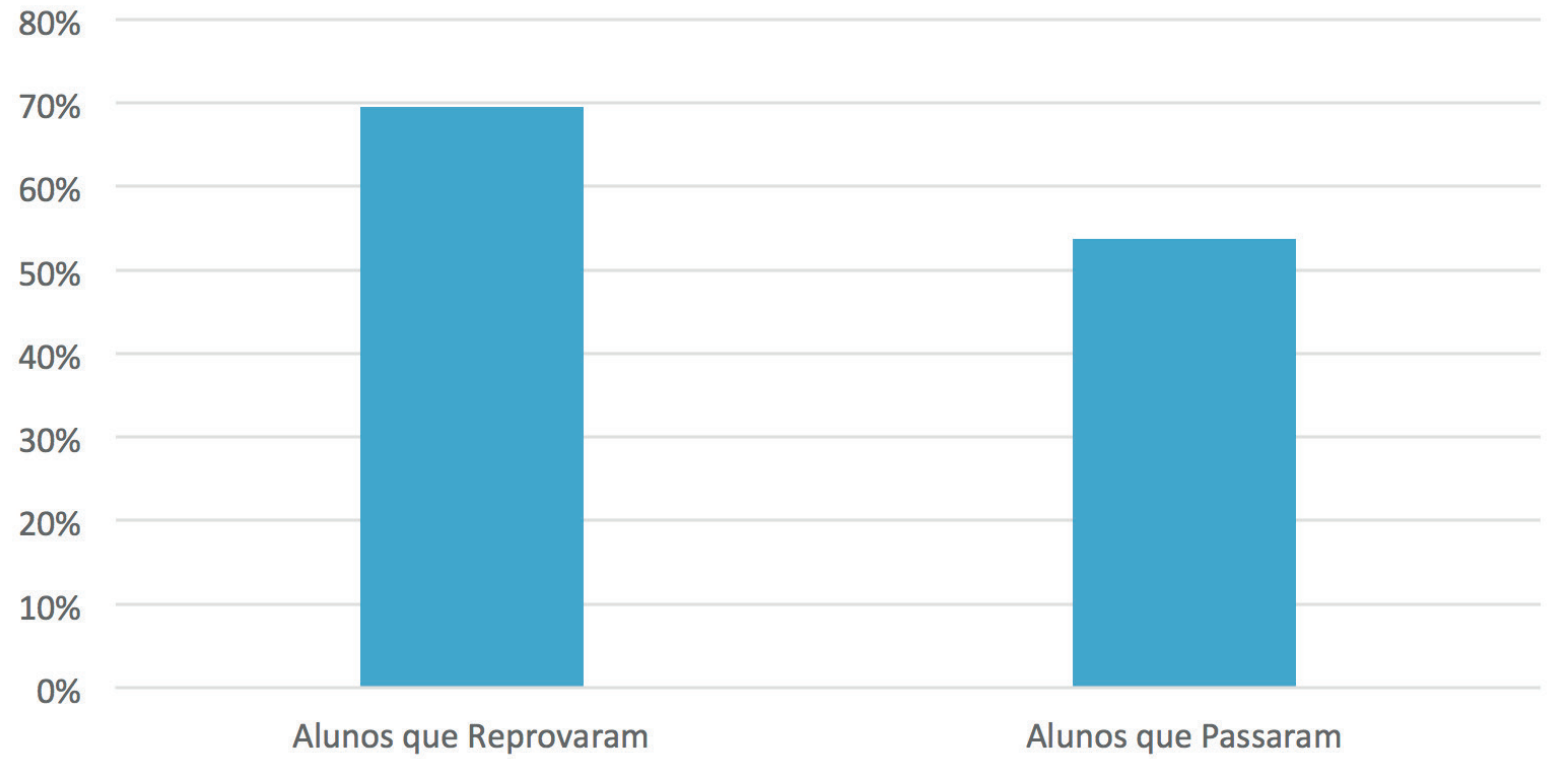

Figura 3. Alunos que sentem nervosismo e ansiedade durante as provas 
É possível, a partir dos dados, observar que a maioria dos alunos, $70 \%$ dos reprovados e $54 \%$ dos aprovados, alegaram que sentem muito ou razoável nervosismo ou ansiedade durante as provas e que isso os atrapalha. Em relação à amostra geral, estes alunos representam, aproximadamente, $60 \%$ do total, o que permite concluir que existe uma relação de percepção por partes dos alunos, da ansiedade em situação de avaliação e a sua possível relação com o desempenho, visto que a maioria dos alunos que reprovaram na disciplina alegou ter o fator "ansiedade" como influenciador do mau desempenho. Para Wigfield e Eccles (1989), a ansiedade pode afetar tanto alunos com alto e baixo desempenho. A Figura 3 permite verificar que esse comportamento apareceu tanto nos alunos que reprovaram quanto naqueles aprovados.

Pesquisas sobre ansiedade desenvolvidas no contexto acadêmico parte das investigações realizadas pelos teóricos da Psicologia Cognitiva baseada no Processamento da Informação (Costa \& Boruchovitch, 2004). Aos adeptos dessa abordagem, a ansiedade assume o papel de um constructo multidimensional, formado por dois aspectos distintos, mas que têm relação entre si: a preocupação e a emotividade (Costa \& Boruchovitch, 2004, Wigfield \& Eccles, 1989). Nas análises conjuntas das respostas do bloco I e do bloco II, foi possível observar que os alunos relatam um destes aspectos: a emotividade. Esta assume o seu papel perante a percepção dos alunos, que vai ao encontro do nível que a ansiedade e o nervosismo os atrapalham durante as situações de avaliação.

Para tentar explicar o baixo desempenho de alunos ansiosos em provas, duas interpretações são usadas, a interferência (Wine, 1971; Wigfield \& Eccles, 1989) e o déficit (Benjamin et al., 1981). Quanto à interferência, a hipótese é de que alunos com alta ansiedade fracassam na situação de prova porque dividem sua atenção entre as exigências da tarefa e sentimentos de autodepreciação, o que diminui o nível de concentração e o desempenho (Costa \& Boruchovitch, 2004). Nesse caso, assume-se que existiu a aprendizagem, mas que, devido à ansiedade causada pela situação de avaliação, o aluno não consegue demonstrar. Pelos resultados da pesquisa, foi destacado pelos alunos que existe a presença da ansiedade como barreira no momento de retomar o que se foi aprendido, ou seja, durante as provas ou avaliações.

Quanto ao déficit, o baixo desempenho de alunos altamente ansiosos pode ser explicado por dois aspectos: as deficiências nos hábitos de estudo e nas estratégias de aprendizagem usadas na preparação para as situações de avaliação, sendo que esses déficits ocorrem tanto no momento da aquisição quanto no armazenamento do conhecimento (Costa \& Boruchovitch, 2004).

Dessa forma, o problema está na interferência que a ansiedade tem no processo de aprendizagem. Os alunos ansiosos tendem a ter dificuldade em absorver o conteúdo que é repassado a eles e apresentam também deficiências nos hábitos adotados para os estudos, agravando ainda mais a situação. Tal interpretação não pode ser encontrada de forma clara neste estudo, porém, houve relatos de que possíveis causas da reprovação foram que os alunos não realizavam a resolução dos exercícios ou não conseguiam adotar uma maneira correta de estudar tal matéria, deixando de lado os detalhes que são extremamente fundamentais em tal disciplina. Essa situação é apresentada por Costa e Boruchovitch (2004), que afirmam que pesquisas estão demonstrando que os alunos pouco ansiosos possuem hábitos de estudo e estratégias para a preparação de situações de avaliação mais adequados quando comparados aos alunos muito ansiosos, pois estes não possuem qualidade na sua dedicação aos estudos e sofrem com o baixo desempenho.

\subsection{Discurso do Sujeito Coletivo (DSC)}

Uma das metodologias adotadas para a análise dos dados foi o DSC, sendo utilizado para a análise das respostas obtidas com a questão de . $^{\circ}$ 5: Por que você acredita que os alunos reprovam na disciplina de Contabilidade de Custos?

Conforme abordado anteriormente, segundo Lefèvre e Lefèvre (2005), para a construção do DSC, é necessária a utilização das figuras metodológicas, sendo estas: expressões-chaves, ideias centrais e ancoragem. Como procedimento inicial, foi realizada a leitura e a transcrição literal de todas as respostas. Após esta primeira etapa, as ideias centrais de cada resposta foram devidamente destacadas e classificadas 
em três categorias: dificuldade, desinteresse e ambas. Posteriormente, com base nessas categorias, houve uma classificação das respostas com o objetivo de elaborar o DSC da amostra alvo desta pesquisa. Desta forma, o discurso apresentado na Tabela 4 engloba as respostas obtidas dos alunos aprovados e reprovados na disciplina de Contabilidade de Custos. Destacadas no grupo estão as ideias retiradas e transcritas literalmente dos discursos analisados.

\section{Tabela 4}

\section{Discurso do Sujeito Coletivo}

Eu acredito que os alunos reprovam na disciplina de contabilidade de custos, pois é uma matéria difícil e exige muita dedicação por parte dos alunos e também por parte dos professores. Das disciplinas cursadas no $1^{\circ}$ ano, esta apresentou grande dificuldade para alguns alunos, talvez a complexidade em alguns assuntos, como conceitos e departamentalização e a falta de assimilação do conteúdo tenham contribuído para a reprovação nesta disciplina.

A reprovação também pode ser por vários fatores, por dificuldade de aprendizado, falta de comprometimento ou, até mesmo, a ansiedade ou o nervosismo durante as provas são considerados fatores agravantes. É possível elencar que o tempo de duração da disciplina também pode dificultar o processo de aprendizagem. Ainda, a falta de dedicação também agrava a situação, além da compreensão do conteúdo repassado em sala de aula; é necessário também que haja a realização dos exercícios sobre o conteúdo; a não realização e a não compreensão destes corroboram a reprovação. Existem também alguns casos em que os alunos, por não possuírem base de conhecimentos suficientes para interpretar o conteúdo proposto, não conseguem um bom desempenho na disciplina.

Ainda, um outro possível motivo para a reprovação na disciplina de Contabilidade de Custos ser tão elevada, acredito que seja por ter que aprender uma quantidade de conteúdo muito grande em pouco tempo. Assim, por ser uma matéria que não é tão fácil e pelo tempo de conteúdo reduzido, não há muito tempo para assimilar, fazendo com que os alunos tenham mais dificuldade para conseguir a aprovação.

Em algumas situações, a reprovação pode ter ocorrido devido à dificuldade em lidar com cálculos, dificuldades pessoais, ou por ser uma matéria difícil que exige mais dedicação, tanto dos alunos quanto dos professores. Ainda, por ser uma disciplina que envolve muitos detalhes, os alunos podem e na maioria das vezes não dão a devida preocupação a certos pontos e detalhes, faltando dedicação e empenho.

Uma outra questão que faz parte do leque de motivos da reprovação na disciplina de Contabilidade de Custos e merece atenção é que os alunos não reconhecem a sua importância justamente por não conhecerem a sua prática no mercado, e mais uma vez gera a falta de dedicação e, por consequência, faz com que os alunos não levem a disciplina com tanto rigor e dedicação.

Alguns alunos sentem dificuldades com o método de aula adotado pelo professor, ou não se identificam com o método de aula utilizado, causando assim deficiência no aprendizado. Falta também, por parte dos alunos, a interpretação correta e a aplicabilidade do conteúdo; a falta destes corrobora que os alunos demonstrem cada vez mais a falta de dedicação e de interesse pela disciplina.

É importante destacar também que existem alunos que sentem dificuldades e alunos que não se interessam pela matéria e preocupam-se mais com as outras disciplinas por acharem que a Contabilidade de Custos não é importante. Talvez falte a devida noção de aplicação no mercado de trabalho, ou esta falta de interesse seja realmente só pela falta de aptidão ou vontade.

Mediante este processo metodológico adotado (DSC), foi possível verificar, por parte dos alunos, qual a visão sobre as possíveis causas de reprovação na disciplina. O leque de possíveis motivos e causas foi variado, mas sempre tendendo a razões que levam à falta de dedicação e à falta de interesse por parte dos alunos.

\section{Considerações Finais}

O índice de reprovação na disciplina de Contabilidade de Custos, objeto deste estudo, representa aproximadamente uma média de $42 \%$ em relação ao período de 2008 a 2013 . Sendo este percentual significativo para a instituição, houve a investigação para uma análise mais aprofundada, tendo como amostra os próprios alunos que já cursaram tal disciplina, com o objetivo de identificar os possíveis motivos desse índice de reprovação. Depois de coletados os dados, este estudo buscou embasamento teórico na Teoria da Procrastinação e na abordagem da Psicologia Cognitiva baseada na Teoria do Processamento da Informação para entender seus achados. 
A partir das respostas obtidas nos 102 questionários, houve a aglomeração dos perfis dos respondentes e a análise mais aprofundada, permitindo assim a criação de um possível perfil para os alunos aprovados e para os alunos reprovados na disciplina de Contabilidade de Custos. Posteriormente surgiram dois desdobramentos referentes ao objetivo principal, sendo estes o percentual referente aos alunos que reprovaram por nota e os alunos que reprovaram por falta, respectivamente, $16 \%$ e $27 \%$.

Para cada desdobramento referente ao percentual de reprovação, foi possível observar que existem duas vertentes de possíveis causas para a reprovação destes alunos, classificadas neste estudo como dificuldade e desinteresse. Para uma tentativa de análise parcial sobre os alunos reprovados por nota, utilizou-se a variável ansiedade, classificada como dificuldade como possível colaboradora, a partir da abordagem da Psicologia Cognitiva baseada na Teoria do Processamento da Informação. Para a análise parcial sobre os alunos reprovados por falta, utilizou-se a variável falta de dedicação e desinteresse, com sua fundamentação na Teoria da Procrastinação.

Foi possível observar que a maioria dos alunos (70\% dos reprovados e $54 \%$ dos aprovados) alegaram que sentem muito ou razoável nervosismo ou ansiedade durante as provas e isso os atrapalha. Esses dados indicam que existe a percepção da ansiedade pelos alunos em situação de avaliação e a sua possível relação com o desempenho. Corroborando isso, a maioria dos alunos que reprovaram na disciplina alegou ter o fator ansiedade como influenciador do mau desempenho. Para os alunos, existe a presença da ansiedade como barreira no momento de retomar o que se foi aprendido durante as provas ou avaliações. Esses achados são semelhantes aos da literatura sobre a ansiedade em situações de avaliação, ansiedade escolar e a abordagem da Psicologia Cognitiva baseada na Teoria do Processamento da Informação.

Houve também relatos com as possíveis causas da reprovação, cujos alunos não realizavam a resolução dos exercícios ou não conseguiam adotar uma maneira correta de se estudar tal matéria, deixando assim de lado os detalhes que são extremamente fundamentais em tal disciplina. Tal situação é apresentada por Costa e Boruchovitch (2004), que afirmam que pesquisas estão demonstrando que os alunos pouco ansiosos possuem hábitos de estudo e estratégias para a preparação de situações de avaliação mais adequadas quando comparadas aos alunos muito ansiosos - estes não possuem qualidade na sua dedicação aos estudos e sofrem com o baixo desempenho.

Dentro do leque elencado pelos respondentes como possíveis causas ou motivos que levam os alunos à reprovação na disciplina de Contabilidade de Custos, coube dar destaque à falta de dedicação, ao desinteresse e também à complexidade da disciplina. No que tange a esta última, a maioria das justificativas foi devido à disciplina ter a necessidade de envolvimento com cálculos e muitos detalhes específicos de cada método de custeio, sendo assim considerada por alguns alunos como disciplina "muito difícil".

Quanto à falta de dedicação e ao desinteresse por parte de aluno, os fatores mais representativos elencados pelos respondentes foram a falta de resolução de exercícios, a falta de interesse do aluno em participar da aula, a frequência com que o aluno assistia às aulas e a falta de tempo dedicada aos estudos fora e, até mesmo, dentro da sala de aula. Esses comentários são semelhantes ao abordado pela literatura sobre a Teoria da Procrastinação.

Foi verificado também que o comportamento de postergar a realização de tarefas afeta diretamente a frequência do aluno em sala de aula, visto que, ao colocar outras atividades no lugar das atividades acadêmicas, este pode acumular faltas durante o período letivo e ao final obter uma reprovação por falta. Outro motivo também ligado à procrastinação acadêmica e que pode levar o aluno a abandonar a disciplina, obtendo a reprovação por falta, é o mau desempenho logo no início do período da disciplina, ao postergar a realização das tarefas ou até mesmo postergar o ato em si de estudar. $\mathrm{O}$ aluno obtém um desempenho extremamente insatisfatório e o sentimento de falha leva-o ao abandono da disciplina e à reprovação por falta.

Os achados indicaram alguns dos possíveis motivos para a reprovação na disciplina investigada, como a ansiedade, a falta de dedicação, o desinteresse e a complexidade da disciplina. Com isso, é possível verificar que medidas ou estratégias podem ser adotadas para tentar reduzir o índice de reprovação, sendo que alguns dependem do aluno e outros do professor. Tão importante quanto mapear as causas dos problemas é tentar 
resolvê-los, pois, conforme já comentado, o alto custo de manter um aluno na universidade pública e a necessidade de disseminação do conhecimento como forma de melhorar uma sociedade são motivos mais do que suficientes para promover a análise e a solução de problemas envolvidos com o ensino/aprendizagem.

Mais pesquisas são necessárias para dar sustentação, contradizer, refinar ou expandir os achados desta pesquisa. Como sugestão para futuros trabalhos, pode-se destacar a necessidade do uso de medidas para a procrastinação e medidas de desempenho como forma de entender os motivos que levam alunos à reprovação ou à evasão.

\section{Referências}

Ackerman, D. S., Gross, B. L. (2005). My instructor made me do it: task characteristics of procrastination. Journal of Marketing Education, 27(1), pp. 5-13.

Alexander, E. S., Onwuegbuzie, A. J. (2007). Academic procrastination and the role of hope as a coping strategy. Personality and Individual Differences, 42(7), pp. 1301-1310.

Beck, B. L., Koons, S. R. \& Milgrim, D. L. (2000). Correlates and consequences of behavioral procrastination: the effects of academic self-esteem and self-handicapping. Journal of Social Behavior and Personality,15(5), pp. 3-13.

Benjamin, M., McKeachie, W. J., Lin, Y. \& Holinger, D. P. (1981). Test anxiety: deficits in information processing. Journal of Education Psychology, 73(6), pp. 816-824.

Borralha, S. da. (2012) Ansiedade em situações de avaliação. O portal dos psicólogos. Disponível em: $<$ http://www.psicologia.pt/artigos/textos/A0648.pdf >. Recuperado em 9/7/2014.

Brownlow, S. \& Reasinger, R. D. (2000). Putting off until tomorrow what is better done today: academic procrastination as a function of motivation toward college work. Journal of Social Behavior and Personality, 15(5), pp. 15-34.

Burns, L. R., Dittmann, K., Nguyen, N.-L. \& Mitchelson, J. K. (2000). Academic procrastination, perfectionism, and control: associations with vigilant and avoidant coping. Journal of Social Behavior and Personality, 15(5), pp. 35-46.

Conceiçao, J. P. O. DA. (2011). Personalidade e procrastinaçao em estudantes universitários. Dissertaçao de Mestrado - Universidade Lusófona de Humanidades e Tecnologias - Lisboa: Portugal.

Costa, E. R. \& Boruchovitch, E. (2004). Compreendendo relações entre estratégias de aprendizagem e a ansiedade de alunos do ensino fundamental de Campinas. Psicologia: Reflexão e Crítica, 17(1), pp. 15-24.

Culler, R. E. \& Holahan, C. (1980). Test anxiety and academic performance: the effects of study-related behaviors. Journal of Educational Psychology, 72(1), pp. 16-20.

Enumo, S. R. F. \& Kerbauy, R. R. (1999). Procrastinação: descriçao de comportamentos de estudantes e transeuntes de uma capital brasileira. Resvista Brasileira de Terapia Comportamental e Cognitiva, 1(2), pp. 125-133.

Fee, R. L. \& Tangney, J. P. (2000). Procrastination: A Means of avoiding shame or guilt? Journal of Social Behavior and Personality, 15(5), pp. 167-184.

Fontes, J. J. O. (2012). Procrastinação: classificação dos hábitos de procrastinação digital no ambiente académico de uma turma do $1^{\circ}$ ano de Design e criação de método curricular pedagógico autorregular da aprendizagem. Dissertaçao de Mestrado - Faculdade de Engenharia da Universidade do Porto - Porto: Portugal. 
Garzella, F. A. C. (2013). A disciplina de cálculo I: análise das relações entre as práticas pedagógicas do professor e seus impactos nos alunos. Tese de Doutorado - Universidade Estadual de Campinas - Faculdade de Educação. Campinas, São Paulo-SP. Brasil.

Hipólito, O. (2011). País perde 9 bolhões com evasão no ensino superior. Recuperado em 04 agosto, 2014 de http://g1.globo.com/educacao/noticia/2011/02/pais-perde-r-9-bilhoes-com-evasao-no-ensino-superior-diz-pesquisador.html.

Howell, A. J., Watson, D. C., Powell, R. A. \& Buro, K. (2006). Academic procrastination: The pattern and correlates of behavioural postponement. Personality and Individual Differences, 40(8), pp. 1519-1530.

Jackson, T., Weiss, K. E. \& Lundquist, J. J. (2000). Does procrastination mediate the relationship between optimism and subsequent stress? Journal of Social Behavior and Personality, 15(5), pp. 203-212.

José, A. B. \& Silva, R. (1989). O Problema da Ansiedade nas provas: perspectivas contemporâneas. Revista Semina, 10(3), pp. 190-195.

Kağan, M., Çakir, O., İlhan, T. \& Kandemir, M. (2010). The explanation of the academic procrastination behaviour of university students with perfectionism, obsessive - compulsive and five factor personality traits. Procedia - Social and Behavioral Sciences, 2(2), pp. 2121-2125.

Henneberry, J. K. (1976). Initial progress rates as related to performance in a personalized system of instruction. Teaching of Psychology, 3, pp. 178-181.

Klassen, R. M., Krawchuk, L. L. \& Rajani, S. (2008). Academic procrastination of undergraduates: low self-efficacy to self-regulate predicts higher levels of procrastination. Contemporary Educational Psychology, 33(4), pp. 915-931.

Knaus, W. J. (2000). Procrastination, blame, and change. Journal of Social Behavior and Personality, 15(5), pp. 153-166.

Lefèvre, F. \& Lefèvre, A. M. C. (2005). Discurso do sujeito coletivo: um novo enfoque em pesquisa qualitativa (desdobramentos). $2^{\mathrm{a}}$ ed. Caxias do Sul, RS: Educs.

Lefèvre, F., Lefèvre, A. M. C. \& Marques, M. C. DA C. (2009). Discurso do sujeito coletivo, complexidade e auto-organização. Ciência e Saúde Coletiva, 14(4), pp. 1193-1204.

Lloyd, K. E. \& Knutzen, N. J. (1969). A self-paced programmed undergraduate course in the experimental analysis of behavior. Journal of Applied Behavior Analysis, 2(2), pp. 125-133.

Mattar, F. N. (2001). Pesquisa de marketing: uma orientaçao aplicada. $3^{a}$ ed. São Paulo: Atlas.

Martins, G. A. \& Theóphilo, C. R. (2007). Metodologia da investigação científica para ciências sociais aplicadas. São Paulo: Atlas.

Meyer, C. L. (2000). Academic Procrastination and self- handicapping: gender differences in response to noncontingent feedback. Journal of Social Behavior and Personality, 15(5), pp. 87-102.

Michaelis, on line. Recuperado em 05 agosto, 2014 de http://www. http://michaelis.uol.com.br/.

Odaci, H. (2011). Academic self-efficacy and academic procrastination as predictors of problematic internet use in university students. Computers \& Education, 57(1), pp. 1109-1113.

Onwuegbuzie, A. J. (2000). Academic procrastinators and perfectionistic tendencies among graduate students. Journal of Social Behavior and Personality, 15(5), pp. 103-109.

Owens, A. M. \& Newbegin, I. (2000). Academic procrastination of adolescents in english and mathematics: gender and personality variations. Journal of Social Behavior and Personality, 15(5), pp. 111-124.

Pychyl, T. A., Lee, J. M. \& Blunt, A. (2000). Five days of emotion: an experience sampling study of undergraduate student procrastination. Journal of Social Behavior and Personality, 15(5), pp. 239-254. 
Resolução do Conselho Universitário nº 07, 1972. Universidade Estadual de Maringá [UEM].

Ribeiro, F., Avelino, B. C., Colauto, R. D., Casa Nova, S. P. C. (2014). Comportamento procrastinador e desempenho acadêmico de estudantes do curso de Ciências Contábeis. Anais VIII Congresso Anpcont. Rio de Janeiro, RJ, Brasil.

Rissi, M. C. \& Marcondes, M. A. S. (2011). Estudo sobre a reprovação e retenção nos cursos de graduação: 2009. UEL. Londrina, PR, Brasil.

Rotenstein, A., Davis, H. Z. \& Tatum, L. (2009). Early birds versus just-in-timers: the effect of procrastination on academic performance of accounting students. Journal of Accounting Education, 27(4), pp. 223-232.

Sampaio, R. K. N. \& Bariani, I. C. D. (2011). Procrastinaçao acadêmica: um estudo exploratório. Estudos Interdisciplinares dem Psicologia, 2(2), pp. 242-262.

Schwartz, G. E. (1976). What is doing the teaching in PSI courses. In L. E. Fraley \& E. A. Vargas (Eds.), Behavior research and technology in higher education. Gainesville, FL: Society for Behavioral Technology and Engineering, University of Florida. pp. 35-40

Semb, G., Glick, D.M., \& Spencer, R.E. (1977). Programmatic research: An analysis of student withdrawals in behavioral systems of instruction. In: Fourth national conference on behavior research and technology in higher education, Pittsburg, September 30-October 1.

Silva, R. R. C. M., Mainier, F. B. \& Passos, F. B. A (2006). Contribuição da disciplina de introdução à engenharia química no diagnóstico da evasão. Ensaio: avaliaçao e política públicas em Educaçao, 14(51), pp. 261-277.

Silva Filho, R. L. L., Motejunas, P. R., Hipólito, O. \& Lobo, M. B. C. M. (2007). A evasão no ensino superior brasileiro. Cadernos de Pesquisa, 37(132), pp. 641-659.

Specter, M. H. \& Ferrari, J. R. (2000). Time orientations of procrastinators: focusing on the past, present, or future? Journal of Social Behavior and Personality, 15(5), pp. 197-202.

Solomon, L. J. \& Rothblum, E. D. (1984). Academic procrtastination: frequency and cognitive-behavioral correlates. Journal of Counseling Psychology, 31(4), pp. 503-509.

Vieira, C. \& Cristóvão, D. (2009). Contributos para um diagnóstico do insucesso escolar no ensino superior: a experiência da Universidade de Évora. Cadernos PRPQI, n. ${ }^{\circ} 10$.

Wigfield, A. \& Eccles, J. S. (1989). Test anxiety in elementary and secondary school students. Educational Psychologist, 24(2), pp. 159-183.

Wine, J. (1971). Test anxiety and direction of attention. Psychological Bulletin, 76(2), pp. 92-104. 